\title{
Knowledge Acquisition Gaps: A Comparison of Print versus Online News
}

\section{Sources}

\author{
JungAe Yang \& Maria Elizabeth Grabe
}

\begin{abstract}
This experimental study tested the knowledge gap hypothesis at the intersection of audience education levels and news formats (newspaper versus online). The findings reveal a gap in public affairs knowledge acquisition between South Korean citizens $(N=123)$ from different educational backgrounds. Moreover, the high education group comprehended news with the same level of efficiency across online and newspaper formats while low education participants gained more knowledge from reading a newspaper than using the online news source. Taken together, this study's findings confirm the knowledge gap hypothesis through experimental research and offer evidence of its potential contribution to the digital divide.
\end{abstract}

Key words: Knowledge gap, learning from news media, digital divide, online news, information processing, comprehension of news, news exposure, new media, traditional media. 
Democracies are built on the premise of informed citizens who perform their civic duties and exercise their rights as citizens (Delli Carpini \& Keeter, 1996). It is therefore no surprise that scholars across the world have paid considerable attention to the media's influence on how citizens acquire public affairs information (Price \& Czilli, 1996). One strain of research in this tradition focuses on the varying potential of media formats (e.g. newspaper, television, online) to inform citizens. Another prominent line of inquiry concentrates on differential knowledge gain across different socioeconomic groups, or the so-called knowledge gap phenomenon (see Gaziano, 1983, 1997; Viswanath \& Finnegan, 1996). Both research areas serve as signposts for the current study that aims to test the knowledge gap across old (newspaper) and emerging (online) formats.

Some scholars (Bonfadelli, 2002; Jerit, Barabas, \& Bolsen, 2006; Prior, 2005; van Dijk \& Hacker, 2003) have argued that the explosion of information volume and source diversity created by new media might exacerbate information disparities. Yet, few studies have offered assessments of the relative size of education-based information gaps across old and emerging media. To gain insight into how different media might influence knowledge acquisition gaps, one has to parse together studies form (1) the body of literature referred to as learning from media, (2) information access studies, and (3) recent work on education-based knowledge gaps across old and new media using surveys and experiments. Valuable as they are, these three bodies of literature are built on data collected from mostly U.S. citizens. The study reported here collected data from South-Korean citizens and followed the recent experimental turn in knowledge gap research with focus on the potential of traditional and emerging media to vary in their influence on knowledge gaps.

South Korea's soaring broadband Internet adoption rates and the high average education 
levels of its citizens make for a challenging setting to study the intersection of the knowledge gap and the digital divide. Most of what we know about the knowledge gap is based on data collected from citizens who live in heterogeneous societies with relatively large variation in emerging media adoption rates and socio-economic status of citizens. If education based gaps in knowledge acquisition exist, they would arguably be most readily observable in such heterogeneous societies. South Korea, on the other hand, is quite homogenous in terms of ethnicity, national language, and education levels — especially compared to the U.S. In 2008, 70.5\% of South Koreans between 18 and 21 (defined as the college going age) were enrolled in institutions of higher education (Korean Ministry of Education, Science and Technology, 2010) while the percentage of Americans was 26.7\% that year (U.S. Census Bureau, 2010). South Korea is also a leading country in Internet adoption rates, particularly in broadband Internet service subscription. According to the official statistics of the International Telecommunication Union (2009) or ITU, $76.50 \%$ of South Koreans were Internet users in 2008. This figure is significantly higher than the world average (23.44 \%), with South Korea ranking eleventh out of 233 countries around the world. The U.S. ranked seventeenth. Interestingly, 100\% of Internet subscribers in Korea are broadband service subscribers - the world average is around $73 \%$.

To advance our insight into both the knowledge gap and the digital divide it seems imperative to move investigations beyond the relative heterogeneity of contemporary North American and European societies and into relatively uncharted homogeneous social territory. Indeed, if education based gaps are observed in such settings, the veracity of existing theoretical positions could be advanced.

\section{The Knowledge Gap Revisited}

The essence of the knowledge gap theory is captured in the well-known phrase of its 
founders: “....as the infusion of mass media information into a social system increases, segments of the population with higher socio-economic status tend to acquire this information at a faster rate than the lower status segments, so that the gap in knowledge between these segments tends to increase rather than decrease" (Tichenor, Donohue, \& Olien, 1970, p. 159). Over the course of 40 years, knowledge gap research has consistently demonstrated differential knowledge gain across education or socio-economic status (SES) groups (Eveland \& Scheufele, 2000; Gaziano, 1983). People with higher levels of education, who typically have more rehearsed information processing skills (Eveland \& Scheufele, 2000; Grabe, Lang, Zhou, \& Bolls, 2000; Jerit, et al., 2006; D. M. McLeod \& Perse, 1994), broader and deeper background knowledge (Price \& Zaller, 1993; Tichenor, et al., 1970), and more thoroughgoing interest in public affairs issues, acquire more information than less educated people.

Critical to the evolution of knowledge gap research was the development of distinct methods for testing gap formation. First, education-based knowledge acquisition has been assessed over time (at least two points) as media publicity on issues increase (Tichenor, et al., 1970). The difference in knowledge levels between education groups is predicted to increase over time. Second, Tichenor et al. (1970) recommended a cross-sectional approach by examining the correlation between education and knowledge acquisition across topics highly and less publicized in media. Issues receiving more media coverage are predicted to produce larger knowledge gaps than issues less featured in the media spotlight. Third, Eveland and Scheufele (2000) argue that media use (light or heavy) in conjunction with the education variable can be used to test a knowledge gap at any given point in time. Beginning with McLeod, Bybee, and Durall (1979), a number of researchers have adopted this method (e.g., Eveland \& Scheufele, 2000; Grabe, Yegiyan, \& Kamhawi, 2008; Kwak, 1999). 
With resemblance to the third method of testing the knowledge gap, this study adopted media use as an individual level variable that might influence information gain across education groups. The following two hypotheses serve as the starting point for testing the knowledge gap both in terms of differential exposure to and acquisition of public affairs information.

H1: More educated people will expose themselves to more public affairs news than less educated people.

H2: More educated people will acquire more public affairs knowledge from news media use than less educated people.

\section{Online News versus Newspaper Knowledge Gaps}

A number of studies have compared knowledge gap formation across media formats (Donohue, Olien, \& Tichenor, 1987; Donohue, Tichenor, \& Olien, 1973; Eveland \& Scheufele, 2000; Kwak, 1999; J. M. McLeod, et al., 1979; Neuman, Just, \& Crigler, 1992), and some recent studies have included online news as a media type (Grabe, Kamhawi, \& Yegiyan, 2009; Kim, 2008). Yet, the majority of studies compared television and newspaper information gain. Given the world-wide growth in online news consumption (see Pew Research Center, 2008) and the correlating decline in traditional news media use, more format comparison studies that include the online condition are needed. Even in a related research area-known as learning from the media studies - comparisons of knowledge gain across traditional and new media are limited, knowledge measures are often not comparable, and results are often contradictory. Viewed comprehensively, this body of literature does offer some evidence that print media have an edge (at least in the amount of acquired information) over online media (see Eveland, 2003; Eveland \& Dunwoody, 2002, for reviews). There is, however, clear consensus that online and newspaper format comparisons are methodologically more readily doable than print and television (or radio) 
(Norris \& Sanders, 2003). Yet, one should not underestimate the structural and organizational variance between newspapers and websites - differences that pose experimental design opportunities, challenges, and different outcome expectations.

\section{Story Importance Cues}

Newsroom workers not only select what will be reported but also decide what level of prominence to assign to selected news stories. Through these decisions, or gatekeeping, news editors and reporters provide story importance cues to news consumers. The space dedicated to a newspaper story, its placement in the paper, headline size, and the size and number of photographs featured with it are regarded as signals of its relative importance (Eveland, Marton, \& Seo, 2004; Fico, Heeter, Soffin, \& Stanley, 1987; Knobloch-Westerwick, Sharma, Hansen, \& Alter, 2005; Tewksbury \& Althaus, 2000). Newspaper readers have been shown to follow these cues both in terms of the importance they assign to stories and their exposure decisions. For example, long articles on the front page are rated as more important than short stories featured on the inside pages (Althaus \& Tewksbury, 2002) and prominence cues guide decisions about story exposure (Graber, 1984, 1988).

Editorial cues are less prevalent in the online environment, primarily because of technological differences (Tewksbury \& Althaus, 2000). First, the relatively small size of computer (and cell-phone) screens requires information in compact form (Althaus \& Tewksbury, 2002). Visual cues such as large headlines or photos are therefore infrequently used on the home pages of news websites (Tewksbury \& Althaus, 2000). Most stories are positioned in subordinate lists by topical menu (e.g., politics, sports, international news) or by time of uploading with little variation in headline size (Eveland, et al., 2004; Fico, et al., 1987; Heeter, Brown, Soffin, Stanley, \& Salwen, 1989). Second, frequent online updates make it impractical to arrange news stories by 
order of importance (Johnson \& Kelly, 2003; Tewksbury \& Althaus, 2000). Articles are therefore often placed in the order of recency rather than story importance. Third, due to the hypertext organization of the Web, users click on headlines to access article pages (Knobloch-Westerwick, et al., 2005) without knowing the length of stories (traditional news importance cue) before accessing them. Thus, the menu-based structure of online news enables news consumers to identify news stories of interest while ignoring topics of limited interest (Dozier \& Rice, 1984; Fico, et al., 1987; Heeter, et al., 1989; Tewksbury \& Althaus, 2000).

Differences in structural features across print and online news formats might prompt variance in story selection. Story importance cues and the linear structure of newspapers might promote inadvertent exposure to public affairs news, especially in the case of readers who have low interest in such topics. On the other hand, less salient editorial cues and the index structure of online news allow more pointed news story selection and thereby less accidental exposure to public affairs news. It can therefore be expected that news users would be exposed to more public affairs news using print than online news formats, leading to the third hypothesis.

H3: Newspaper readers will be exposed to more public affairs news than online news users.

\section{User Control versus Cognitive Load}

Decreased editorial influence and increased user control are expected to impact user learning from media. Hypermedia is often described as more conducive to learning than the print format because it offers high levels of user control. User (or learner) control refers to the extent to which users pace and sequence information access, as well as the amount and range of exposure to content (Milheim \& Martin, 1991). Proponents of user control theory argue that the flexibility of hypermedia and its interactive features empowers users to create a learning 
environment that matches their unique cognitive abilities, background knowledge, interests, and learning styles (see Eveland \& Dunwoody, 2001; 2002, for reviews). This proposition rests on the assumption that learners are aware of their own cognitive strengths. A number of researchers (e.g., Fastrez, 2001; Last, O'Donnell, \& Kelly, 2001; Scheiter \& Gerjets, 2007) have challenged this assumption by arguing that high user control might undermine learning by imposing a heavy cognitive burden. The hypermedia structure demands high levels of attention to navigate, sapping cognitive resources for making decisions about links to follow, how to get to information, and how that information is positioned in the larger information volume. Conklin (1987) called this demand on resources during navigation "cognitive overhead" and a number of researchers (e.g., Conklin, 1987; Darken \& Sibert, 1996; Marchionini, 1988; McDonald \& Stevenson, 1996) have studied the feeling of being disoriented in cyberspace. The high level of user control in the online news environment might impose a cognitive burden that leads to lower levels of learning among users, prompting the following hypothesis.

H4: Newspaper readers will acquire more public affairs knowledge than online news users.

\section{At the Intersection of Audience Education Level and News Format}

While hypothesis four is grounded in existing research that shows how user control leads to disorientation in mediated environments, some studies have qualified the sweeping scope of this idea. Indeed, evidence of cognitive overload (or disorientation) during hypermedia use among less knowledgeable users exists (e.g., Last, et al., 2001; McDonald \& Stevenson, 1998) and point to either low system expertise or domain knowledge as contributing factors. On the other hand, more experienced learners sometimes profit from hypermedia's flexibility (see DeStefano \& LeFerve, 2007; Scheiter \& Gerjets, 2007, for comprehensive reviews). In terms of 
learning outcomes, hypermedia users with high levels of system knowledge performed well regardless of the media format they use - and outperformed those with lower levels of knowledge (e.g., Balcytiene, 1999; Potelle \& Rouet, 2003).

Education is positively related to hypermedia system experience. In fact, the digital divide literature (Bonfadelli, 2002; Bozionelos, 2004; van Dijk \& Hacker, 2003) has demonstrated significant education-based (or SES-based) gaps in computer hardware ownership, access to computers and the Web, and digital skills. Moreover, content-specific uses of ICTs (Information and Communication Technologies) differ across education groups. High education groups tend to use new media for informational purposes (e.g., news reading) while lower education groups typically use new information technologies for entertainment purposes (e.g., playing electronic games) and prefer television as their primary news source. In fact, they read newspapers less often than high education groups (Donohue, et al., 1987; D. M. McLeod \& Perse, 1994; Neuman, et al., 1992). Thus, low education groups have relatively little experience with both newspapers and online formats which make them more susceptible to media-supplied salience cues (Iyengar \& Kinder, 1987). Story importance cues, typical of the newspaper format, could therefore be expected to have more influence on story selection of lower than higher education groups. At the same time, the index-based organization of online news enables users to identify news of interest. As a result, less educated people, who have been shown to have lower interest in public affairs, will be more likely to avoid this type of news when they use the online than newspaper format. More educated people, who generally follow public affairs news closely, are expected to pursue such information regardless of news format.

Coupled with these expected variations in news exposure, different levels of system (hypermedia) and domain (public affairs) expertise across the two education groups are likely to 
further influence public affairs information gain. Less educated people with relatively low levels of expertise are expected to experience more navigational problems during hypermedia than print media use, while more educated people with relatively high levels of knowledge might not experience such problems. This prompts predictions of two interaction effects for education and news format:

H5: There will be an interaction effect such that less educated people will expose themselves to less public affairs news using the online than newspaper source, while more educated people's exposure to public affairs news will not vary across the two news sources.

H6: There will be an interaction effect such that less educated people will acquire less public affairs knowledge from online than newspaper use, while more educated people's knowledge acquisition on public affairs will not vary across the two news sources.

\section{Method}

\section{Design and Independent Variables}

An audience education ( 2 levels: high and low) by presentation mode ( 2 levels: print and online news) between-subjects factorial design was used in this experiment.

Audience education: High and low. In line with previous studies (e.g., Grabe, et al., 2000), participants in the high education group either completed a graduate degree (M. S., M.A., or Ph.D.) or were enrolled in graduate programs at the time of participation while the low education group was represented by participants with no more than a high school diploma. High education participants were recruited through advertisements posted on bulletin boards and on the website of an urban Seoul university where the experiment was conducted. To draft participants with lower levels of education, the advertisement was placed in free newspapers 
distributed in the neighborhood of the university. Low education group participants were also recruited from computer classes sponsored by local government offices. To control for the novelty of using unfamiliar media, all subjects who participated in this experiment had experience using the Web for news consumption. Based on research findings of inverse correlations between age and online news use (National Internet Development Agency of Korea, 2007; Pew Research Center, 2008), people over 60 were excluded. Moreover, young adults are unlikely to have had the opportunity to complete high levels of education. As a result, participants in their mid-20s to late 50 s were recruited for the experiment and age was added as a covariate together with five media use variables. One-hundred-and-twenty-three volunteers who satisfied the subject selection parameters participated in the experiment -74 and 49 participants for the high and low education groups respectively. The age and Internet news use parameters and the relative educational homogeneity of South Korean society, posed serious challenges in recruiting low education subjects. To achieve gender balance across different experimental conditions, near equal numbers of men and women from each education group were assigned to the two media presentation mode groups.

Presentation mode: Online and newspaper. To advance external validity, this study used a professional newspaper (The Chosun Ilbo) and its Web-based version (www.chosun.com) as experimental stimuli. The Chosun Ilbo has the largest national readership in South Korea. Because of frequent online updates a static version, matching the day's print version of The Chosun Ilbo, was built to assure informational consistency. Advertisements were included as they appeared on the original site. Moreover, a recommendation system ("most viewed") was included to provide news importance cues in the same way that editorial cues (headline size, article length) do in newspapers (Knobloch-Westerwick, et al., 2005). Video clips, news blogs, 
chat rooms, news story search functions, and links to other related stories were excluded from the experimental site in order to match information volume across conditions.

To avoid major breaking news that would become highly salient, a slow news day was chosen and a month time-lapse between stimuli selection and data collection served as an attempt to advance memory decay for exposure to news stories.

There were a total 104 news stories, two thirds were public affairs news. The print version featured breaking news (including politics), national, local, international, culture, sports, and people sections. ${ }^{1}$ The online version offered breaking news, politics, national, international, culture, and sports menus. "Local" and "People" news in the online version were located under the "National" and "Culture" menus respectively. The following sections/menus were regarded as public affairs news: politics, breaking news, national, local, and international sections (see Tewksbury \& Althaus, 2000). ${ }^{2}$ In line with Tewksbury and Althaus (2000), this study treated public affairs news as information necessary for citizens to perform surveillance of their expanded and immediate worlds, with the potential for social empowerment and participation in democratic processes. With few exceptions (e.g., Jerit, et al., 2006), previous research tested knowledge gaps on a single or a small number of topics. Although valuable to theory building, testing the knowledge gap on a single topic has shortcomings. As Moore (1987) pointed out, issues are diffused to the public in a curvilinear (s-curve) rather than linear manner. The point on the curve at which data is collected might explain, at least in part, increasing or declining knowledge gaps. By testing a large number of topics with different levels of diffusion it is possible to counter potential influences of the diffusion curve.

\section{Dependent Variables}

News exposure. The current study is invested in preserving the agency of media users 
in news consumption. Specifically, participants were allowed to exercise their exposure preferences for news content (public affairs versus entertainment) during the experiment. Behavioral observation is arguably a more reliable measure of news exposure than self-report procedures (Papper, Holmes, \& Popovich, 2004; Tewksbury, 2003). Trained observers recorded on log sheets the chronology and time participants spent on each page of the newspaper. Page numbers were marked, in advance, on the upper right or left corner of each page so that observers were able to see them from a distance. For the online news condition, log files of page view chronologies and exposure time were programmed when the experimental website was produced. For the newspaper condition the observation method provided participant exposure time to each newspaper page while log files for the online news condition offered the exact exposure time to each news story. To make these two measures statistically comparable proportions of exposure time to public affairs and entertainment news stories were calculated for each medium.

Knowledge acquisition. Distinctions between understanding and remembering news have been drawn in information processing studies (e.g., Robinson \& Levy, 1986; Snoeijer, de Vreese, \& Semetko, 2002; Woodall, Davis, \& Sahin, 1983). Comprehension involves more than memory for discrete information. Subsequently, measures of how well participants integrate information into a meaningful system of existing knowledge have been developed. In line with Robinson and Levy (1986) memory was first triggered by asking the participants of this study to briefly describe all the news stories they remember using 5 to 10 words per story. Following this, participants described in detail what they remembered about the news stories they listed during the first task. Participant responses were analyzed and scored following the coding scheme devised by Robinson and Levy (1986, p. 111). Central to this measure is the identification of a 
main point to each story. Three professional journalists served as independent assessors of the main points in the experimental stories - with no disagreement (Cohen's Kappa $=1)$. With the identified main points in hand, two coders were trained to analyze the comprehension responses. As a reliability check on the primary coder, the secondary coder examined $10 \%$ (randomly selected) of the comprehension responses. The inter-coder reliability (Cohen's Kappa) was at .63, well within the range of "substantial" agreement (Landis \& Koch, 1977). Participant scores, which ranged from 0 to 8 , were summed to construct the final knowledge acquisition score.

Media use variables as covariates. Several media use variables, expected to influence the relationships between independent and dependent variables, were used as covariates for statistical control. Weekly Internet use, online news use, and newspaper use were assessed with two sequential questions. First, participants were asked to estimate their frequency of media use with six choices (nearly every day, 3 to 5 days per week, 1 or 2 days per week, once every few weeks, less often, and never). In the subsequent question, they reported the approximate time spent on a day they used a given medium. To construct a weekly media use measure, similar to Althaus and Tewksbury (2000), responses to the first closed-ended question were treated as a scale of daily media use $(7,4,1.5,0.25,0.05$, and 0$)$ and multiplied by the responses to the second open-ended question. To assess potential pre-exposure to experimental stimuli, participants were asked to estimate the frequency with which they use The Chosun Ilbo and its website, using the same six choices of the other media use measures.

\section{Procedure}

This study was conducted in a computer laboratory at a large university in South Korea. Upon arrival participants were randomly assigned to either the print or the online news condition. Participants in both experimental groups were asked to use the medium for 15 minutes as they 
normally do. Limiting the exposure to 15 minutes encouraged selective exposure among participants - an important dimension for this study. After the reading/browsing sessions, participants completed post-test questionnaires, were thanked, debriefed, and paid for their participation.

\section{Results}

To test the main and interaction effects of education and presentation mode on news exposure and knowledge acquisition, Education (2) x Presentation Mode (2) ANCOVA tests with covariates were conducted for public affairs news exposure and public affairs knowledge acquisition.

\section{News Exposure Findings $(\mathrm{H} 1, \mathrm{H} 3 \text {, and } \mathrm{H5})^{3}$}

Hypothesis 1 predicted that the high education group would read more public affairs news than the low education group. Contrary to the prediction, there was no difference between the high $(M=77.40, S E=2.53)$ and low $(M=78.29, S E=3.22)$ education groups in terms of news exposure (see Table 1). Yet, the newspaper group $(M=82.96, S E=2.05)$ read more public affairs news than the online news group $(M=72.73, S E=1.93)$, supporting the prediction of hypothesis 3 .

\section{--Insert Table 1 here--}

The interaction effect for education and presentation mode on public affairs news exposure (hypothesis 5) was not significant (see Table 1). It is noteworthy though that in line with the prediction, post-hoc analyses demonstrated that the low education group spent more time reading public affairs news in the newspaper $(M=82.73, S E=4.13)$ than on the Web $(M=$ $73.85, S E=3.60), F(1,41)=4.03, p=.05, \eta^{2}=.09$. The high education group, however, also read more public affairs news in newspapers $(M=83.19, S E=2.90)$ than online $(M=71.62, S E$ 
$=2.97)$, contrary to the prediction, $F(1,66)=11.77, p=.001, \eta^{2}=.15$.

\section{Knowledge Acquisition Findings (H2, H4, and H6)}

As summarized in Table 2, high education participants $(M=38.43, S E=2.05)$

outperformed the lower education group $(M=20.15, S E=2.86)$ in comprehending public affairs news. This finding offers support for hypothesis 2 . Moreover, as hypothesis 4 predicted, newspaper readers $(M=32.11, S E=1.79)$ comprehended public affairs news better than online news users $(M=26.47, S E=1.63)$.

\section{--Insert Table 2 here--}

The interaction effect for education and presentation mode on public affairs knowledge acquisition (hypothesis 6) approached statistical significance (see Table 2 and Figure 1). ${ }^{4}$ Subsequent post-hoc analyses revealed that the comprehension scores for the low education group was indeed significantly higher for the newspaper $(M=24.96, S E=3.72)$ than online $(M=$ $15.35, S E=3.07)$ condition, $F(1,39)=12.45, p=.001, \eta^{2}=.24$. Also in line with hypothesis 6 predictions, more educated participants did not differ in comprehension scores across the two media conditions $(M s=39.26,37.59, S E s=2.50,2.57), F(1,64)=.04, p=.84, \eta^{2}=.00$. That is, their mean difference (1.67) in comprehension between the print and online condition was significantly smaller, compared to less educated participants (mean difference $=9.61)$. Taken together these findings offer support for hypotheses 2,4 , and 6.

--Insert Figure 1 here--

\section{Further Analyses: Comprehension after Controlling for Exposure Levels}

To test the effects of news exposure amount on the relationship among audience education, presentation mode, and knowledge acquisition, news exposure was added as a seventh covariate in subsequent ANCOVA procedures. 
The main effect for participant education on knowledge acquisition remained significant for public affairs knowledge acquisition, $F(1,110)=17.56, p=.001$, partial $\eta^{2}=.14$. The high education group $(M=38.38, S E=2.05)$ acquired more public affairs knowledge than the low education group $(M S=20.20, S E=2.86)$, regardless of news exposure levels.

The main effect for presentation mode on public affairs knowledge acquisition was also robust after controlling for news exposure, $F(1,110)=3.75, p=.05$, partial $\eta^{2}=.03$. Newspaper readers $(M=31.73, S E=1.83)$ acquired more public affairs knowledge than online news users $(M=26.85, S E=1.67)$ regardless of exposure.

Finally, the interaction effect for audience education and presentation mode on public affairs knowledge acquisition remained at a close to significant level, after controlling for news exposure, $F(1,110)=3.03, p=.09$, partial $\eta^{2}=.03 .^{5}$ It is noteworthy that public affairs news exposure failed to produce a significant effect on public affairs knowledge acquisition, $F(1,110)$ $=1.00, p=.32$, partial $\eta^{2}=.01$.

\section{Discussion}

The primary purpose of this study was to investigate the possibility that new media use exacerbates the information gap between different educational groups. The findings of this study offer evidence to answer, "they do," to this large question. Before proceeding with more detailed discussion of this conclusion, the limitations of this study are addressed up front.

As a means to control for pre-exposure to the experimental stimuli and other media, a time delay (approximately one month) was built into the design to allow natural memory decay to run its course. Nonetheless, prior exposure to the stimuli and other news media might have affected choices about news exposure in the experiment. News stories featured in the experimental stimuli were evolving over time and appeared in many media outlets as news 
events typically do. Hence, it is likely that in the period between stimuli selection and data collection, the participants - especially heavy news consumers - might have been exposed to some of the news. A ceiling effect from such prior exposure might have prevented participants from paying attention to heavily publicized stories during their participation in the experiment. This possibility should be considered for high education group participants in particular as they tend to be heavy news media users.

Second, The Chosun Ilbo is well known as a conservative newspaper. People with a liberal political orientation are less likely to have favorable views of the paper and therefore also less likely to use this source. Younger readers, who are generally more socially progressive than older folks, can be expected to have less favorable views of this news outlet. Hence, it is likely that younger participants might have avoided some news stories with a conservative bent and this might be particularly true for political news stories. If a liberally oriented newspaper was used as the experimental stimuli, news story selection, especially political news, might have been different.

Third, in a society known for greater educational homogeneity than western countries, the age and new media use parameters used in recruiting participants for this experiment posed serious challenges in recruiting low education subjects. A compromise between statistical power and internal validity was achieved. Indeed, it was deemed crucial to collect data from citizens in low and high education groups who all had experience consuming news through the Internet. The alternative, to maximize statistical power but running the risk that Internet news use be confounded with the all important education factor, defied notions of validity in research. Remarkably, predicted main effects achieved statistical significance at the $p=.05$ level. Only one interaction effect on knowledge acquisition became a point of concern when it approached ( $p$ 
$=.09$ ) the conventional significance point. Post-hoc calculations, using an acceptable power level, effect size, and sample size indeed pointed out that this finding can be treated as substantiation of an interaction effect.

Despite these limitations, the study reported here offers evidence of a digitally-driven knowledge gap. Exposure preferences were significantly influenced by the medium, but not by education level. Specifically, participants in this study exposed themselves to more public affairs news and less entertainment news in newspaper than the online conditions-regardless of their formal education levels. Not surprisingly, newspaper readers also comprehended more public affairs news than online news users. This result is in line with past research (Dozier \& Rice, 1984; Fico, et al., 1987; Heeter, et al., 1989; Tewksbury \& Althaus, 2000).

It is also noteworthy that similar news exposure patterns across different education groups do not result in similar levels of knowledge acquisition. In fact, the high education group outperformed the low educated group in acquiring public affairs information, despite the similar exposure patterns of the two education groups. Lastly, and perhaps most importantly, there was the close to significant interaction effect between education and presentation mode on public affairs news comprehension. Less educated people comprehended significantly more public affairs news from reading a newspaper than using the online source while more educated people delivered similar comprehension performances across the two media. Further analyses, adding exposure as a covariate, did not change the potency of the education or media format effects on knowledge acquisition. Indeed, more educated people do acquire more knowledge from news media use than less educated people, irrespective of exposure levels to public affairs. This gap is most visible for online news consumption.

The findings reported here suggest that emerging news media might exacerbate the 
existing education-based gap on cognitive engagement with socially important issues. Information gaps associated with online news might intensify as the reliance on new media as information sources increases. The majority of citizens still lean on traditional media as their primary news source and use online news formats as complementary (see Ahlers, 2006; Tewksbury, 2006). Yet, the migration from traditional to online sources is expected to increase over time. In particular, the health of the newspaper industry, around the globe, is in rapid decline. Against this backdrop the findings of this study, particularly the larger knowledge gap among online news users, offer a sobering forecast for an escalating digital divide when it comes to textbased knowledge gain. Importantly, these conclusions are based on data collected from South Koreans who live in one of the most technologically wired and homogeneous societies in the world. It seems likely that in more diverse societies where Internet access is less diffused the education-based gap across traditional and emerging media users might even be wider. 


\section{Notes}

1 "Business \& technology" (Section B) and "Other" (Section D) were separate supplemental sections, excluded from experimental stimuli. The "Opinion" portion that featured editorials, columns, and opinions from readers, was also excluded, because it contains interpretations of socially important issues rather than news itself. Three pages of the "Opinion" section in the print version were stapled together in advance so that experimental participants were not exposed to them.

${ }^{2}$ Sports, culture, and people sections were treated as entertainment news. Because no predictions related to entertainment news were made, findings regarding entertainment news will not be reported here.

${ }^{3}$ Because news exposure measures are proportional scales, every participant's scores for public affairs and entertainment news exposure add up to $100 \%$ and each of the two scales has an inverse correlation with the other.

${ }^{4}$ For the reasons explained in the method section, recruiting low education participants posed a major challenge and resulted in a trade-off between statistical power and subject recruitment parameters. Statistically, the alpha-level for this ANCOVA test for a two-by-two interaction with six covariates, with 123 subjects, statistically powered at .80 , should be set at .264 not .050. Thus, the finding here of an effect that "approached significance" at the $p=.090$ is a conservative interpretation. Considering that statistical power was sacrificed in favor of meeting subject age and internet news use parameters, we are confident that this finding indeed offers evidence of an interaction effect.

${ }^{5}$ In line with the calculation reported in note 4, the alpha-level for this ANCOVA test for a two-by-two interaction with seven covariates, with 123 subjects, statistically powered at .80 , 
should be set at .265 not .050 .

\section{References Cited}

Ahlers, D. (2006) 'News Consumption and the New Electronic Media', The Harvard International Journal of Press/Politics 11(1): 29-52.

Althaus, S. L. and Tewksbury, D. (2000) 'Patterns of Internet and Traditional News Media Use in a Networked Community', Political Communication 17(1): 21-45.

Althaus, S. L. and Tewksbury, D. (2002) 'Agenda Setting and the New News: Patterns of Issue Importance among Readers of the Paper and Online Versions of the New York Times', Communication Research 29(2): 180-207.

Balcytiene, A. (1999) 'Exploring Individual Processes of Knowledge Construction with Hypertext', Instructional Science 27(3-4): 303-28.

Bonfadelli, H. (2002) 'The Internet and Knowledge Gaps: A Theoretical and Empirical Investigation', European Journal of Communication 17(1): 65-84.

Bozionelos, N. (2004) 'Socio-Economic Background and Computer Use: The Role of Computer Anxiety and Computer Experience in Their Relationship', International Journal of Human-Computer Studies 61: 725-46.

Conklin, J. (1987) 'Hypertext: An Introduction and Survey', IEEE Computer 20(7): 17-41.

Darken, R. P. and Sibert, J. L. (1996) 'Navigating Large Virtual Spaces', International Journal of Human-Computer Interaction 8(1): 49-71.

Delli Carpini, M. X. and Keeter, S. (1996) What Americans Know about Politics and Why It Matters. New Haven, CT: Yale University Press.

DeStefano, D. and LeFerve, J. A. (2007) 'Cognitive Load in Hypertext Reading: A Review', Computers in Human Behavior 23: 1616-41.

Donohue, G. A., Olien, C. N. and Tichenor, P. J. (1987) 'Media Access and Knowledge Gaps', Critical Studies in Mass Communication 4: 87-92.

Donohue, G. A., Tichenor, P. J. and Olien, C. N. (1973) 'Mass Media Functions, Knowledge and Social Control', Journalism Quarterly 50: 652-9.

Dozier, D. M. and Rice, R. E. (1984) 'Rival Theories of Electronic News Reading' in R. E. Rice, J. H. Blair, M. Chen, J. Dimmick, D. M. Dozier and M. E. Jacob (eds.) The New Media: Communication, Research, and Technology, pp. 103-27. Beverly Hills, CA: Sage.

Eveland, W. P., Jr. (2003) 'A "Mix of Attributes" Approach to the Study of Media Effects and New Communication Technologies', Journal of Communication 53: 395-410.

Eveland, W. P., Jr. and Dunwoody, S. (2001) 'User Control and Structural Isomorphism or Disorientation and Cognitive Load?: Learning from the Web versus Print', Communication Research 28(1): 48-78.

Eveland, W. P., Jr. and Dunwoody, S. (2002) 'An Investigation of Elaboration and Selective Scanning as Mediators of Learning from the Web versus Print', Journal of Broadcasting \& Electronic Media 46(1): 34-53.

Eveland, W. P., Jr., Marton, K. and Seo, M. (2004) 'Moving beyond "Just the Facts": The 
Influence of Online News on the Content and Structure of Public Affairs Knowledge', Communication Research 31(1): 82-108.

Eveland, W. P., Jr. and Scheufele, D. A. (2000) 'Connecting News Media Use with Gps in Knowledge and Participation', Political Communication 17(3): 215-37.

Fastrez, P. (2001) 'Characteristic(s) of Hypermedia and How They Relate to Knowledge', Education Media International 38(2/3): 101-10.

Fico, F., Heeter, C., Soffin, S. and Stanley, C. (1987) 'New Wave Gatekeeping: Electronic Indexing Effects on Newspaper Reading', Communication Research 14(3): 335-51.

Gaziano, C. (1983) 'The Knowledge Gap: An Analytical Review of Media Effects', Communication Research 10(4): 447-86.

Gaziano, C. (1997) 'Forecast 2000: Widening Knowledge Gaps', Journalism \& Mass Communication Quarterly 74(2): 237-64.

Grabe, M. E., Kamhawi, R. and Yegiyan, N. (2009) 'Informing Citizens: How People with Different Levels of Education Process Television, Newspaper, and Web News,' Journal of Broadcasting \& Electronic Media 53(1): 90-111.

Grabe, M. E., Lang, A., Zhou, S. and Bolls, P. D. (2000) 'Cognitive Access to Negatively Arousing News: An Experimental Investigation of the Knowledge Gap', Communication Research 27(1): 3-26.

Grabe, M. E., Yegiyan, N. and Kamhawi, R. (2008) 'Experimental Evidence of the Knowledge Gap: Message Arousal, Motivation, and Time Delay', Human Communication Research 34: $550-71$.

Graber, D. A. (1984) Processing theNnews: How People Tame the Information Tide. New York: Longman.

Graber, D. A. (1988) Processing the News: How People Tame the Information Tide (2nd ed.). White Plains, NY: Longman.

Heeter, C., Brown, N., Soffin, S., Stanley, C. and Salwen, M. (1989) 'Agenda Setting by Electronic Text News', Journalism Quarterly 66(1): 101-6.

International Telecommunication Union (2009) 'Internet Indicators: Subscribers, Users, and Broadband Subscribers, URL (consulted Dec. 2009): http://www.itu.int/ITUD/icteye/Reporting/ShowReport.aspx?ReportFormat=PDF\&ReportName $=\% 2 \mathrm{FWTI} \% 2 \mathrm{FI}$ nformationTechnologyPublic\&RP_intYear=2008\&RP_intLanguageID=1\&ShowReport=t rue

Iyengar, S. and Kinder, D. R. (1987) News That Matters: Television and American Opinion. Chicago: University of Chicago Press.

Jerit, J., Barabas, J. and Bolsen, T. (2006) 'Citizens, Knowledge, and the Information Environment', American Journal of Political Science 50(2): 266-82.

Johnson, T. J. and Kelly, J. D. (2003) 'Have News Media Editors Abandoned the Old Media Ideals? The Journalistic Values of Online Newspaper Editors', The New Jersey Journal of Communication 11(2): 115-34.

Kim, S. H. (2008) 'Testing the Knowledge Gap Hypothesis in South Korea: Traditional News Media, the Internet, and Political Learning', International Journal of Public Opinion Research 20(2): 193-210.

Knobloch-Westerwick, S., Sharma, N., Hansen, D. L. amd Alter, S. (2005) 'Impact of Popularity Indications on Readers' Selective Exposure to Online News', Journal of Broadcasting \& Electronic Media 49(3): 296-313. 
Korean Ministry of Education, Science and Technology (2010) 'Brief Statistics on Korean Education' URL (consulted July 2010): http://cesi.kedi.re.kr/publ/publ_yrbk_tbl.jsp?publ_item_id=1000108140

Kwak, N. (1999) 'Revisiting the Knowledge Gap Hypothesis: Education, Motivation, and Media Use', Communication Research 26(4): 385-413.

Landis, J. R. and Koch, G. G. (1977) 'The Measurement of Observer Agreement for Categorical Data', Biometrics 33: 159-74.

Last, D. A., O'Donnell, A. M. and Kelly, A. E. (2001) 'The Effects of Prior Knowledge and Goal Strength on the Use of Hypermedia', Journal of Educational Multimedia \& Hypermedia 10(1): 3-25.

Marchionini, G. (1988) 'Hypermedia and Learning: Freedom and Chaos', Educational Technology Research \& Development 28(11): 8-12.

McDonald, S. and Stevenson, R. J. (1996) 'Disorientation in Hypertext: The Effects of Three Text Structures on Navigation Performance', Applied Ergonomics 27(1): 61-8.

McDonald, S. and Stevenson, R. J. (1998) 'Effects of Text Structure and Prior Knowledge of the Learner on Navigation in Hypertext', Human Factors 40(1): 18-27.

McLeod, D. M. and Perse, E. M. (1994) 'Direct and Indirect Effects of Socioeconomic Status on Public Affairs Knowledge', Journalism Quarterly 71(2): 433-42.

McLeod, J. M., Bybee, C. R. and Durall, J. A. (1979) 'Equivalence of Informed Political Participation: The 1976 Presidential Debates as a Source of Influence', Communication Research 6: 463-87.

Milheim, W. D. and Martin, B. L. (1991) 'Theoretical Bases for the Use of Learner Control: Three Different Perspectives', Journal of Computer-Based Instruction 18(3): 99-105.

Moore, D. W. (1987) 'Political Campaigns and the Knowledge Gap Hypothesis', Public Opinion Quarterly 51(2): 186-200.

National Internet Development Agency of Korea (2007) 'Survey on the Computer and the Internet Usage, URL (consulted Oct. 2007): http://isis.nida.or.kr/index_unssl.jsp

Neuman, W. R., Just, M. and Crigler, A. (1992) Common Knowledge: News and the Construction of Social Meaning. Chicago: University of Chicago Press.

Norris, P. and Sanders, D. (2003) 'Message or Medium? Campaign Learning during the 2001 British General Election', Political Communication 20: 233-62.

Papper, R. A., Holmes, M. E. and Popovich, M. N. (2004) 'Middletown Media Studies: Media Multitasking ... and How Much People Really Use the Media', The International Digital Media \& Arts Association Journal 1(1): 1-56.

Pew Research Center (2008) 'Audience Segments in a Changing News Environment: Key New Audiences Now Blend Online and Traditional Sources, URL (consulted Aug. 2009): http://people-press.org/reports/pdf/444.pdf

Potelle, H. and Rouet, J. F. (2003) 'Effects of Content Representation and Readers' Prior Knowledge on the Comprehension of Hypertext', International Journal of HumanComputer studies 58(3): 327-45.

Price, V. and Czilli, E. J. (1996) 'Modeling Patterns of News Recognition and Recall', Journal of Communication 46(2): 55-78.

Price, V. and Zaller, J. (1993) 'Who Gets the News? Alternative Measures of News Perceptions and Their Implications for Research', Public Opinion Quarterly 57: 133-64.

Prior, M. (2005) 'News vs. Entertainment: How Increasing Media Choice Widens Gaps in 
Political Knowledge and Turnout', American Journal of Political Science 49(3): 577-92. Robinson, J. P. \& Levy, M. R. (1986) The Main Source: Learning from Television News. Beverly Hills, CA: Sage Publications.

Scheiter, K. and Gerjets, P. (2007) 'Learner Control in Hypermedia Environments', Educational Psychology Review 19: 285-307.

Snoeijer, R., de Vreese, C. H. and Semetko, H. A. (2002) 'Research Note: The Effects of Live Television Reporting on Recall and Appreciation of Political News', European Journal of Communication 17(1): 85-101.

Tewksbury, D. (2003). What do Americans really want to know? Tracking the behavior of news readers on the Internet. Journal of Communication, 53(4), 694-710.

Tewksbury, D. (2006) Exposure to the Newer Media in a Presidential Primary Campaign', Political Communication 23: 313-32.

Tewksbury, D. and Althaus, S. L. (2000) 'Differences in Knowledge Acquisition among Readers of the Paper and OnlineVversions of a National Newspaper', Journalism \& Mass Communication Quarterly 77(3): 457-79.

Tichenor, P. J., Donohue, G. A. and Olien, C. N. (1970) 'Mass Media Flow and Differential Growth in Knowledge', Public Opinion Quarterly 34: 159-70.

U.S. Census Bureau (2010) '2008 Ammerican Community Survey', URL (consulted July 2010): http://factfinder.census.gov/servlet/ADPTable?_bm=y\&-geo_id=01000US\&qr_name=ACS_2008_1YR_G00_DP2\&-ds_name=ACS_2008_1YR_G00_\&lang=en\&-redoLog=false \&-format $=$

van Dijk, J. and Hacker, K. (2003) 'The Digital Divide as a Complex and Dynamic Phenomenon', The Information Society 19(4): 315-26.

Viswanath, K. and Finnegan, J. R., Jr. (1996) 'The Knowledge Gap Hypothesis: Twenty-Five Years Later', Communication Yearbook 19: 187-227.

Woodall, W. G., Davis, D. K. and Sahin, H. (1983) 'From the Boob Tube to the Black Box: Television News Comprehension from an Information Processing Approach', Journal of Broadcasting 27(1): 1-23. 
Table 1

Analysis of Covariance for Public Affairs News Exposure

\begin{tabular}{llcll}
\hline \multicolumn{1}{c}{ Source } & $d f$ & $F$ & $\eta^{2}$ & $p$ \\
\hline Age & 1 & $1.54^{\dagger}$ & .22 & .09 \\
Weekly newspaper use & 1 & .12 & .00 & .73 \\
Weekly Web use & 1 & 6.03 & .05 & .02 \\
Weekly online news use & 1 & .77 & .01 & .38 \\
Pre-exposure to print stimuli & 1 & 1.00 & .01 & .32 \\
Pre-exposure to online stimuli & 1 & .00 & .00 & .99 \\
Education (E) & 1 & .03 & .00 & .86 \\
Presentation mode (P) & 1 & $13.38^{* *}$ & .11 & .00 \\
E x P & 1 & .24 & .00 & .63 \\
Error & 113 & $(.56)$ & & \\
\hline Note. Var & & &
\end{tabular}

Note. Value in parentheses represents mean square error.

${ }^{\dagger} p<.10,{ }^{* *} p<.01$

Table 2

Analysis of Covariance for Public Affairs Knowledge Acquisition

\begin{tabular}{lcccc}
\hline \multicolumn{1}{c}{ Source } & $d f$ & $F$ & $\eta^{2}$ & $p$ \\
\hline Age & 1 & $2.87^{\dagger}$ & .03 & .09 \\
Weekly newspaper use & 1 & 1.72 & .02 & .19 \\
Weekly Web use & 1 & .01 & .00 & .91 \\
Weekly online news use & 1 & .13 & .00 & .72 \\
Pre-exposure to print stimuli & 1 & .48 & .00 & .49 \\
Pre-exposure to online stimuli & 1 & .18 & .00 & .68 \\
Education (E) & 1 & $17.73^{* *}$ & .14 & .00 \\
Presentation mode (P) & 1 & $5.51^{*}$ & .05 & .02 \\
E x P & 1 & $2.83^{\dagger}$ & .03 & .09 \\
Error & 111 & $(154.06)$ & & \\
\hline
\end{tabular}

Note. Value in parentheses represents mean square error.

${ }^{\dagger} p<.10,{ }^{*} p<.05,{ }^{* *} p<.01$ 
Figure 1. The Interaction Effect between Education and Presentation Mode on Public Affairs Knowledge Acquisition

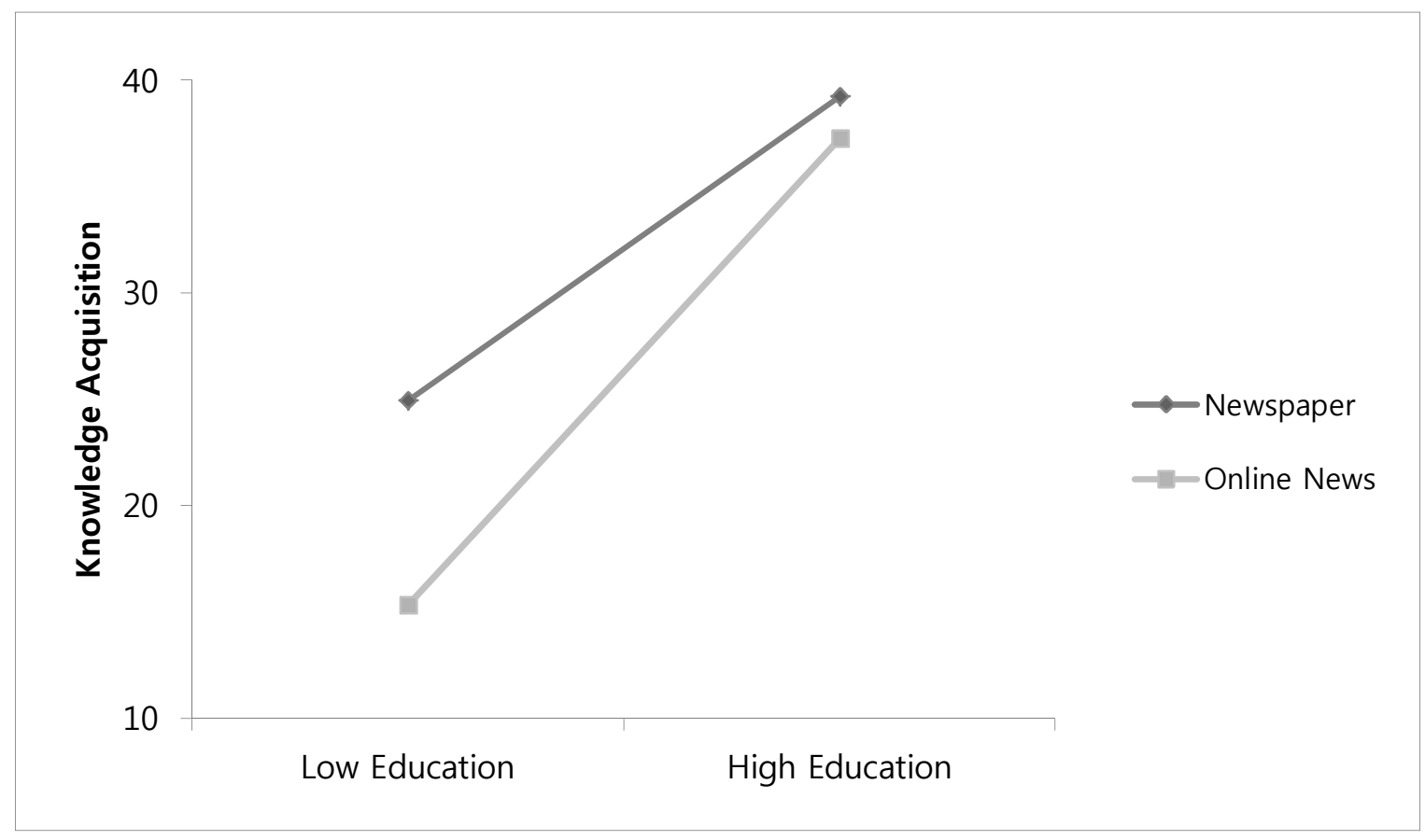

